\title{
Vitamin $E$ inhibits CD95 ligand expression and protects $T$ cells from activation-induced cell death
}

\author{
Min Li-Weber, ${ }^{1}$ Markus A. Weigand, ${ }^{2}$ Marco Giaisi, ${ }^{1}$ Dorothee Süss, ${ }^{1}$ Monika K. Treiber, ${ }^{1}$ \\ Sven Baumann, ${ }^{1}$ Elena Ritsou, ${ }^{1}$ Raoul Breitkreutz, ${ }^{3}$ and Peter H. Krammer ${ }^{1}$ \\ ${ }^{1}$ Tumor Immunology G0300, German Cancer Research Center, Heidelberg, Germany \\ ${ }^{2}$ Department of Anesthesiology, University of Heidelberg, Heidelberg, Germany \\ ${ }^{3}$ Applied Tumor Virology F0600, German Cancer Research Center, Heidelberg, Germany
}

\begin{abstract}
Apoptosis is a morphologically distinct form of cell death involved in many physiological and pathological processes. Expression of the CD95 (APO-1/Fas) ligand (CD95L) is critically involved in activation-induced cell death (AICD) of activated T cells. Here we show that the natural free radical scavenger vitamin $\mathrm{E}$ suppresses the activity of the transcription factors NF- $\mathrm{KB}$ and AP-1, thus blocking expression of CD95L and preventing T cell AICD. Since AICD is a major cause of T cell depletion in AIDS, we examined 35 HIV-1-positive individuals and found that their T cells are more susceptible to AICD than are T cells isolated from healthy controls. Administration of vitamin E suppresses CD95L mRNA expression and protects T cells of HIV-1-infected individuals from CD95-mediated apoptosis. This evidence that vitamin $\mathrm{E}$ can affect $\mathrm{T}$ cell survival may merit further clinical investigation.
\end{abstract}

J. Clin. Invest. 110:681-690 (2002). doi:10.1172/JCI200215073.

\section{Introduction}

CD95 (APO- $1 /$ Fas) is a member of the TNF receptor superfamily expressed on various tissues (1), whereas expression of its ligand (CD95L), a type II transmembrane protein of the TNF family, is more restricted to a few cell types, such as T cells, macrophages, and cells of the testis $(2,3)$. CD95L is not present in resting $T$ cells but is highly expressed upon $\mathrm{T}$ cell activation. Activated $\mathrm{T}$ cells may undergo apoptosis using the CD95/CD95L system (4-7). CD95/CD95L-mediated activation-induced cell death (AICD) is known to play an important role in maintenance of peripheral lymphocyte homeostasis. In HIV-infected patients, AIDS is characterized by a depletion of T cells due, at least in part, to massive apoptosis (8-10). Previously, decreased antioxidant defense and increased levels of lipid peroxides have been found in plasma samples of both HIV-positive individuals and AIDS patients $(11,12)$. These findings are frequently associated with a decrease in vitamin E levels in serum (12). Studies in humans and in mouse models have shown that diet supplementation with vitamin $\mathrm{E}$ increases $\mathrm{CD}^{+}$and total lymphocyte counts (13-15). However, little is

Received for publication January 17, 2002, and accepted in revised form July 9, 2002

Address correspondence to: Peter H. Krammer, Tumor Immunology G0300, German Cancer Research Center, D-69120 Heidelberg, Germany. Phone: 49-6221-423717; Fax: 49-6221-411715; E-mail: p.krammer@dkfz-heidelberg.de. Raoul Breitkreutz present address is: Medical Clinic 2, Johann Wolfgang Goethe Universitätsklinikum, Frankfurt am Main, Germany.

Conflict of interest: No conflict of interest has been declared. Nonstandard abbreviations used: CD95 ligand (CD95L); activation-induced cell death (AICD); forward scatter/side scatter (FSC/SSC); electrophoretic mobility shift assay (EMSA); $\mathrm{T}$ cell receptor (TCR); protein kinase C (PKC). known about the molecular mechanism by which vitamin E enhances T cell numbers.

Vitamin E ( $\alpha$-tocopherol), a naturally occurring effective lipid-soluble antioxidant, can prevent toxicant- and carcinogen-induced oxidative damage by trapping reactive oxyradicals (16). It is a constituent of all cellular membranes and is found in high concentrations in the membranes of immune cells. Vitamin E is essential for normal immune function. Deficiency in vitamin $\mathrm{E}$ has been shown to be associated with increased rates of infection and incidence of tumors $(17,18)$. Vitamin E supplementation has been reported to improve the decreased cellular immune function that occurs during aging and in HIV infection $(18,19)$. Both studies in a mouse AIDS model and epidemiological statistics support the beneficial effects of vitamin $E$ on preventing infection and decreasing the risk of progression to AIDS (19-22).

Since AICD is a major cause of T cell depletion in AIDS (8-10), we asked whether vitamin E could protect from $\mathrm{T}$ cell depletion by AICD. We show here that vitamin E prevents AICD of preactivated normal peripheral blood T cells. CD95 (APO-1/Fas) and its ligand (CD95L) are known to play a major role in AICD of T cells (23). We show that vitamin E suppresses CD95L expression and attenuates AICD by reducing activities of the transcription factors NF- $\mathrm{KB}$ and AP-1 involved in transcriptional regulation of the CD95L gene. Analysis of the influence of vitamin $\mathrm{E}$ on apoptosis of peripheral $\mathrm{T}$ cells from HIV-positive individuals showed a potent effect of vitamin $\mathrm{E}$ on protection of T cells from AICD.

\section{Methods}

Purification of primary buman T lymphocytes. Human peripheral blood mononuclear cells were prepared by Ficoll-Paque (Pharmacia Diagnostic, Freiburg, Germany) density centrifugation. Adherent cells were removed by 
adherence to plastic culture vessels for 1 hour. T cells were isolated from the peripheral blood mononuclear cells by resetting with 2 -amino-ethylisothyo-uronium-bromide treated sheep red blood cells as described (24).

Cell cultures. Primary human T cells and Jurkat T cells were cultured in RPMI supplemented with $10 \%$ heatinactivated FCS (GIBCO BRL, Invitrogen Life Technologies, Karlsruhe, Germany), 10 mM HEPES (GIBCO $\mathrm{BRL}$ ), and $100 \mu \mathrm{g}$ gentamycin $/ \mathrm{ml}$.

$A I C D$. Freshly isolated blood $\mathrm{T}$ cells were stimulated by phytohemagglutinin and cultured in the presence of IL-2 for 6 days as described (24). The T cells were then treated without or with $25 \mu \mathrm{M}$ vitamin E (SigmaAldrich, St. Louis, Missouri, USA) for 1 hour and subsequently cultured in 96-well flat-bottomed plates coated with $\alpha$-CD3 (OKT3, $50 \mu \mathrm{g} / \mathrm{ml}$ ) in the absence or presence of CD95Fc (6) $(50 \mu \mathrm{g} / \mathrm{ml})$ or control human (50 $\mu \mathrm{g} / \mathrm{ml})$ IgG1 (Sigma-Aldrich). Cell death was assessed after a further 48 hours by propidium iodide uptake (24). To determine apoptosis in CD4- and CD8positive T cells, cells were stained with $\alpha$-CD4-FITC and $\alpha$-CD8-PercP mAb (BD Pharmingen, Heidelberg, Germany). Apoptosis was determined by a drop in the forward-to-side-scatter (FSC/SSC) profile of apoptotic in comparison to living cells as described (25).

$\mathrm{J}-27$, a subclone of Jurkat $\mathrm{T}$ cells, $\mathrm{T}$ cells were induced either with PMA (10 ng/ml; Sigma-Aldrich) and ionomycin $(0.5 \mu \mathrm{M}$; Calbiochem-Novabiochem $\mathrm{GmbH}$, Schwalbach, Germany) or with plate-bound $\alpha$-CD3 $(\mathrm{OKT} 3,50 \mu \mathrm{g} / \mathrm{ml})$ for 24 hours in the presence of vitamin $E$ or equal amounts of the vitamin $E$ solvent ethanol. For controls, J-27 cells were stimulated in the absence or presence of CD95Fc $(50 \mu \mathrm{g} / \mathrm{ml})$ or NOK1 $(50 \mu \mathrm{g} / \mathrm{ml})(\mathrm{BD}$ Pharmingen) for 24 hours. Apoptotic nuclei were measured by determination of DNA fragmentation (6).

$\alpha$-APO-1-induced apoptosis was carried out by culturing J-27 cells in the absence or presence of $50 \mu \mathrm{M}$ vitamin $\mathrm{E}$ for 1 hour and then treating them with $\alpha-\mathrm{APO}-1$ antibody (6) $(10 \mathrm{ng} / \mathrm{ml})$ in the presence of 10 $\mathrm{ng} / \mathrm{ml}$ protein $\mathrm{A}$ for the indicated times.

For CD95L analysis, day $6 \mathrm{~T}$ cells were activated by plate-coated $\alpha$-CD3 (OKT3, $40 \mu \mathrm{g} / \mathrm{ml}$ ) in the presence of matrix metalloproteinase (MMP) inhibitors specific for CD95L (MMP inhibitor II, $4 \mu \mathrm{g} / \mathrm{ml}$; CalbiochemNovabiochem $\mathrm{GmbH}$ ). At the indicated time points, cells were collected by centrifugation and washed once with PBS. Cells $\left(5 \times 10^{5}\right)$ were resuspended in $100 \mu \mathrm{l}$ PBS containing $5 \%$ FCS. The cells were incubated with biotin-labeled $\alpha$-CD95L antibody (NOK1, $0.05 \mu \mathrm{g} / \mathrm{ml}$ ) at $4^{\circ} \mathrm{C}$ for 15 minutes. We detected bound antibodies by adding $100 \mu \mathrm{l} \mathrm{PBS}$ containing $0.025 \mu \mathrm{g} / \mathrm{ml}$ Streptavidin-phycoerythrin and incubated them at $4^{\circ} \mathrm{C}$ for a further 15 minutes. Cells were washed once with PBS and resuspended in $200 \mu \mathrm{lPBS}$ and subjected to FACS (FL2 histogram) analysis.

$R N A$ preparation. The day $6 \mathrm{~T}$ cells and freshly isolated peripheral blood $\mathrm{T}$ cells from HIV-positive individuals were precultured with $25 \mu \mathrm{M}$ vitamin $\mathrm{E}$ or equal amounts of vitamin E solvent ethanol for 1 hour and then stimulated for 12 hours with plate-bound $\alpha$-CD3 antibodies. For Jurkat cells, $50 \mu \mathrm{M}$ vitamin $\mathrm{E}$ was administered. RNA was isolated using the RNeasy kit (QIAGEN GmbH, Hilden, Germany) according to the manufacturer's instructions.

Normal RT-PCR. One microgram of total RNA was reverse-transcribed using the RT-PCR kit (Perkin-Elmer Applied Biosystems, Foster City, California, USA). Aliquots were amplified in a DNA thermocycler (Stratagene, Heidelberg, Germany) with $2.5 \mathrm{U}$ recombinant Taq polymerase (Sigma-Aldrich) as described previously (26). Amplification products were separated by electrophoresis on $1.2 \%$ agarose gels. Primers used for detecting CD95L, IFN- $\gamma$, and $\beta$-actin are: for CD95L, sense $5^{\prime}(386)$ ATAGGATCCATGTTTCTGCTCTTCCACCTACAGAAGGA-3' and antisense $5^{\prime}(843)$-ATAGAATTCTGACCAAGAGAGGCTCAGATACGTTGAC-3'; for IFN- $\gamma$, sense 5'(487)-AGTTATATCTTGGCTTTTCA- $3^{\prime}$ and antisense $5^{\prime}(882)$-ACCGAATAATTAGTCAGCTT- $3^{\prime}$; and for $\beta$-actin, sense $5^{\prime}$-TGACGGGGTCACCCACACTGTGCCCATCTA-3' and antisense $5^{\prime}$-CTAGAATTTGCGGTGGACGATGGAGGG- $3^{\prime}$.

Real-time quantitative PCR. The principle of real-time quantitative PCR has been previously described in detail (27). The primers and fluorescently labeled probes used in these studies are CD95L forward primer $5^{\prime}(508)$ AAAGTGGCCCATTTAACAGGC-3', reverse primer 5'(599)AAAGCAGGACAATTCCATAGGTG- $3^{\prime}$, and probe $5^{\prime}(542)$ TCCAACTCAAGGTCCATGCCTCTGG- ${ }^{\prime}$; and $\beta$-actin (used as an internal standard) forward primer $5^{\prime}(2141)$-ACCCACACTGTGCCCATCTACGA-3', reverse primer $5^{\prime}(2435)$ CAGCGGAACCGCTCATTGCCAATGG-3', and probe 5'(2217)-ATGCCCTCCCCCATGCCATCCTGCGT-3'. PCR was performed in a $12.5-\mu \mathrm{l}$ reaction mixture (PCR kit from Eurogentec, Ivoz-Ramet, Belgium) that contained $0.08 \mu \mathrm{g}$ of reverse-transcribed cDNA, $1.25-7.5 \mathrm{pM}$ forward primers, $22.5 \mathrm{pM}$ reverse primers, and $5 \mathrm{pM}$ probe. For each sample, three PCRs were performed. The resulting relative increase in reporter fluorescent dye emission was monitored by TaqMan system (GeneAmp 5700 sequence detection system and software; Perkin-Elmer Applied Biosystems). The level of the CD95L mRNA, relative to $\beta$-actin, was calculated using the following for-

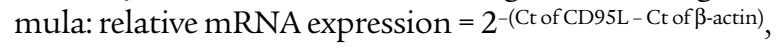
where $\mathrm{Ct}$ is the threshold cycle value.

Preparation of nuclear extracts and electrophoretic mobility shift assay. Jurkat $\mathrm{T}$ cells were preincubated with $50 \mu \mathrm{M}$ vitamin $\mathrm{E}$ or equal amounts of the vitamin $\mathrm{E}$ solvent ethanol for $1 \mathrm{~h}$ and then stimulated by PMA $(10 \mathrm{ng} / \mathrm{ml})$ and ionomycin $(0.5 \mu \mathrm{M})$ for $2 \mathrm{~h}$. Nuclear proteins were isolated as described previously (28). ${ }^{32} \mathrm{P}$-labeled oligonucleotides containing the CD95L NF- $\mathrm{KB}$ sites at the promoter -530 and -50 region (28) and AP- 1 site at the promoter +90 region (26) were analyzed by electrophoretic mobility shift assay (EMSA) as described (28).

Plasmid constructs and transient transfections. Luciferase reporter constructs containing the $0.86-\mathrm{kb}$ CD95L promoter or multimers of the CD95L NF- $\mathrm{KB}$ binding sites at the -530 and -50 regions were used as described previously (20). Three copies of the CD95L AP-1 
$\left(5^{\prime}\right.$-GGGCTGGCCTGACTCACCAGCTGC- $3^{\prime}$ at the +90 region) (26) or the Egr consensus (5'-CCCGGCGCGGGGGCGATTTCGAGTCA - $3^{\prime}$ ) binding sequence were generated by ligation of each DNA sequence into the multicloning site of the pATAT-Luc vector (20). Jurkat $\mathrm{T}$ cells were transfected by electroporation as previously described (28). After overnight recovering, the cells were divided and treated with vitamin $\mathrm{E}(50 \mu \mathrm{M})$ or the vitamin $\mathrm{E}$ solvent ethanol for 1 hour and then further cultured in the absence or presence of PMA $(10 \mathrm{ng} / \mathrm{ml})$ and ionomycin $(0.5 \mu \mathrm{M})$ for 8 hours. Luciferase activity was determined as previously described (28).

Antibodies. The $\alpha$-p50, $\alpha$-JunB, and $\alpha$-JunD antibodies were purchased from Santa Cruz Biotechnology Inc. (Santa Cruz, California, USA). The $\alpha-\mathrm{NF}-\mathrm{\kappa B} / \mathrm{p} 65$ was purchased from Biomol Research Laboratories Inc. (Butler Pike, Pennsylvania, USA). The $\alpha$-Jun/Fos and $\alpha$-JunB antibodies were kindly provided by P. Angel (German Cancer Research Center, Heidelberg, Germany).

\section{Results}

Vitamin E protects restimulated peripheral blood $T$ cells from apoptosis. To analyze the effect of vitamin $\mathrm{E}$ on $\mathrm{T}$ cell death, freshly isolated peripheral blood $\mathrm{T}$ cells were prestimulated for 6 days (then referred to as day 6 cells)
(24) and subsequently restimulated via the T cell receptor (TCR) by plate-bound $\alpha$-CD3 antibodies. Restimulation of the day $6 \mathrm{~T}$ cells resulted in AICD (Figure 1a). CD95 and CD95L play an important role in AICD of T cells. In the presence of the CD95 blocker CD95Fc, AICD was largely inhibited (Figure 1a). A similar inhibition of AICD was obtained in the presence of $25 \mu \mathrm{M}$ vitamin $\mathrm{E}$ in the culture medium (Figure 1a). The concentration of vitamin $\mathrm{E}$ in plasma from healthy individuals normally ranges from 12 to $35 \mu \mathrm{M}$ (29). Administration of different amounts of vitamin $\mathrm{E}$ showed that vitamin $\mathrm{E}$ at physiological concentrations may attenuate AICD in T cells (Figure 1b). Depending on the blood donor, vitamin E reduced AICD by $25-65 \%$ (Figure 1b). Correspondingly, CD95L expression levels were substantially reduced in $\mathrm{T}$ cells treated with vitamin E (Figure 1c). Kinetic analysis showed that, in the presence of vitamin E, significant reduction of CD95L expression in $\mathrm{T}$ cells could be observed after 12 hours of activation (Figure 1d).

Thus, vitamin $\mathrm{E}$ at physiological concentrations may attenuate AICD. Indeed, depending on the blood donors, vitamin $\mathrm{E}$ reduced AICD by $20-50 \%$ (data not shown). Since CD95-mediated AICD is regulated by CD95L expression (4-7), we examined CD95L mRNA
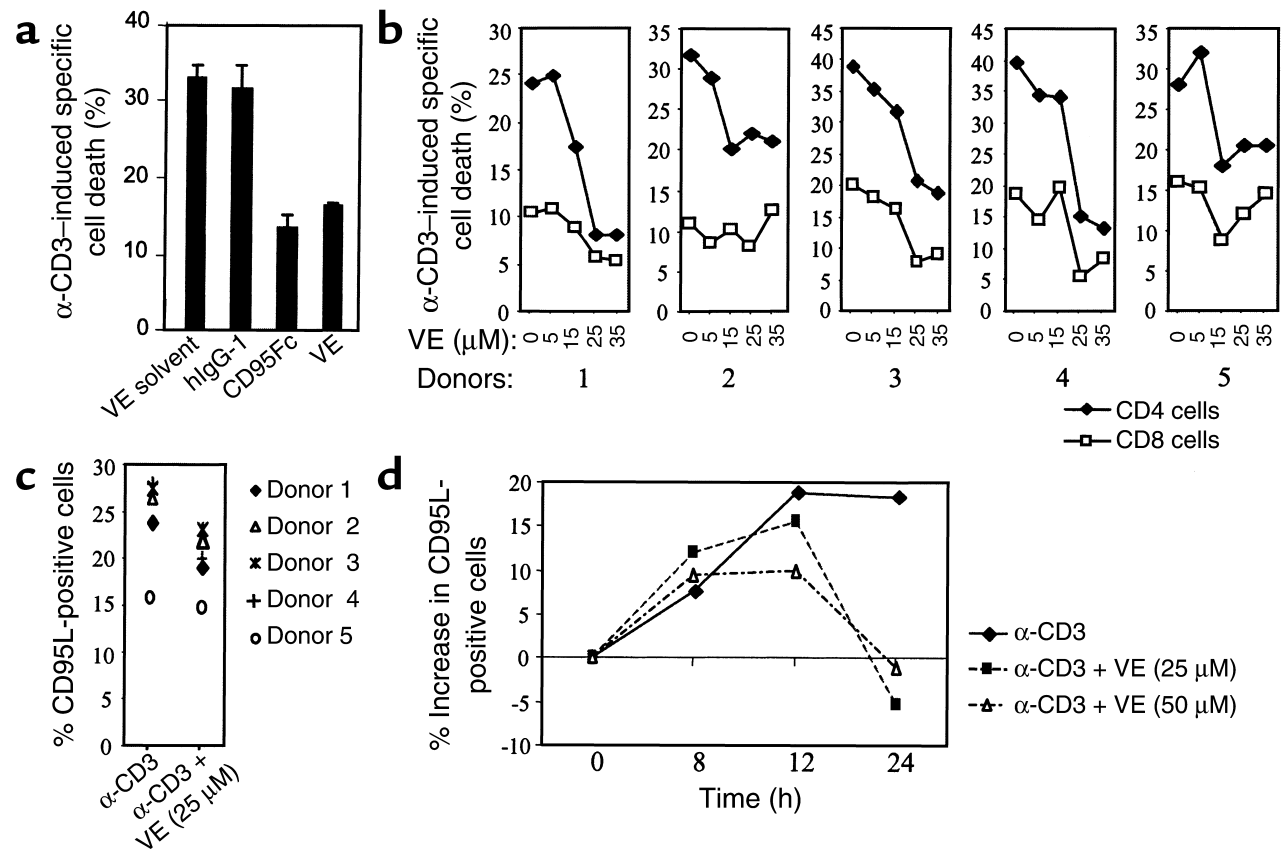

\section{Figure 1}

Vitamin E prevents AICD and suppresses CD95L expression of human peripheral blood T cells. (a) Vitamin E prevents AICD. The day 6 prestimulated peripheral blood T cells were either left alone or pretreated with vitamin $E(V E)$ and subsequently restimulated with $\alpha$-CD3 (OKT3) in the absence or presence of CD95Fc or control human IgG1. Cell death was assessed after a further 48 hours by propidium iodide uptake. Results represent one experiment done in duplicates. (b) Vitamin E downregulates AICD in a dose-dependent manner. The day $6 \mathrm{~T}$ cells prepared from five different donors were restimulated with $\alpha-C D 3$ in the absence or presence of different amounts of vitamin E. Percentage of apoptotic CD4 and CD8 T cells were determined after 36 hours by FSC/SSC analysis. (c) Vitamin E downregulates CD95L protein expression levels. T cells from the donors in $\mathbf{b}$ were activated with $\alpha-C D 3$ in the absence and presence of $25 \mu \mathrm{M}$ vitamin $\mathrm{E}$ and metalloproteinase inhibitors to increase expression of the membrane-bound ligand. After 16 hours' activation, cell-surface expression levels of CD $95 \mathrm{~L}$ protein were measured by FACS. (d) Kinetic analysis of the effect of vitamin E on CD95L protein expression. T cells from donor 3 were activated with $\alpha$-CD3 in the absence and presence of 25 or $50 \mu \mathrm{M}$ vitamin $\mathrm{E}$ and metalloproteinase inhibitors. Cells were collected at different time points as indicated, and cell-surface expression levels of CD95L protein were measured by FACS. 

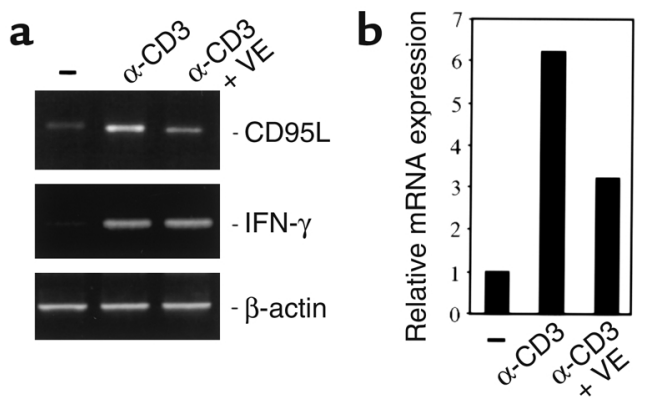

\section{Figure 2}

Vitamin E suppresses CD95L mRNA levels. (a) Analysis of the vitamin $E$ effect on CD95L mRNA expression levels by RT-PCR. The day $6 \mathrm{~T}$ cells were treated without or with vitamin $\mathrm{E}$ and then stimulated for 12 hours with $\alpha$-CD3. The CD95L mRNA expression levels were analyzed by RT-PCR. For controls, IFN- $\gamma$ and $\beta$-actin mRNA levels were examined. (b) Quantification of the CD95L mRNA expression levels by real-time PCR. The expression value of CD95L in unstimulated cells was set as transcription value 1 . The expression value of CD95L in $\alpha$-CD3-stimulated cells is shown as fold difference relative to that of unstimulated cells.

expression levels in activated $\mathrm{T}$ cells in the presence or the absence of vitamin E. Restimulation of day $6 \mathrm{~T}$ cells led to enhanced expression of CD95L mRNA. This increase was blocked in the presence of vitamin E (Figure 2a). To evaluate CD95L mRNA expression levels in the presence of vitamin $\mathrm{E}$, the RNA was analyzed by real-time PCR. Approximately 50\% reduction of CD95L mRNA expression was seen (Figure 2b). In contrast, vitamin $\mathrm{E}$ did not significantly influence the levels of IFN- $\gamma$ mRNA (Figure 2a). Thus, downregulation of CD95L expression may account for the reduction of AICD by vitamin E.

Vitamin E protects apoptosis in activated Jurkat $T$ cells. Jurkat T cells express both CD95 and CD95L and have been used as a model system for apoptosis studies (6). To further investigate the molecular mechanism by which vitamin $\mathrm{E}$ attenuates AICD, we selected several Jurkat T cell subclones susceptible to TCR-mediated activation-induced apoptosis. Data from one of the representative clones, clone $27(\mathrm{~J}-27)$, are presented here. Activation of T cells through the TCR can be mimicked by stimulation with phorbol ester (PMA) and calcium ionophores (ionomycin). Both $\alpha$-CD3induced cell death and PMA/ionomycin-induced cell death in J-27 cells were significantly reduced by vitamin $\mathrm{E}$ (Figure 3 , $\mathrm{a}$ and $\mathrm{b}$ ). As controls, the CD95 blocker CD95Fc or the CD95L blocking antibody NOK1 greatly inhibited AICD (Figure 3c). However, vitamin E did not prevent $\mathrm{mAb} \alpha-\mathrm{APO}-1$-induced CD95-triggered apoptosis (Figure 3d). Therefore, it is unlikely that vitamin E directly interferes with signals downstream of the CD95 receptor. Analysis of CD95L mRNA expression showed that, upon TCR activation, CD95L mRNA in J-27 cells was rapidly induced and its expression increased for up to 12 hours. In the presence of vitamin $\mathrm{E}$, however, CD95L mRNA expression was substantially reduced (Figure 3e). Quantification of the CD95L mRNA levels by real-time PCR showed that reduction was readily seen at 3 hours of induction and was nearly completely blocked by vitamin E 6

\section{Figure 3}

Protection of Jurkat J-27 T cells from AICD by vita$\min$ E. ( $(\mathbf{a}$ and $\mathbf{b}$ ) Vitamin E prevents apoptosis in J-27 T cells. J-27T cells were induced either with PMA and ionomycin (iono.) or with plate-bound $\alpha$-CD3 for 24 hours in the presence of vitamin $E$ or equal amounts of the vitamin E solvent ethanol. Apoptotic nuclei were measured by determination of DNA fragmentation. (c) The CD95L blocker CD95Fc and NOK1 blocked AICD. J-27 cells were stimulated as above in the absence or presence of CD95Fc or NOK1 for 24 hours. (d) Vitamin E does not block $\alpha-\mathrm{APO}-1-$ induced apoptosis. J-27 cells were treated without or with vitamin $\mathrm{E}$ and then treated with $\alpha$-APO- 1 antibody for the indicated times. Results are shown from one of three reproducible experiments done with duplicates. (e) Vitamin E downregulated CD95L mRNA expression in J-27 cells. J-27 T cells were cultured in the absence or presence of vitamin $E$ and then stimulated by PMA and ionomycin for the indicated times. CD95L mRNA expression was analyzed by RT-PCR. IFN- $\gamma$ and $\beta$-actin mRNA expression levels were examined for control. (f) Quantification of the CD95L mRNA expression levels by real-time PCR. RNA at $0,1,3$, and 6 hours after stimulation was subjected to real-time PCR. The expression value of CD95 L at time 0 was set as transcription value 1 . The expression value of $C D 95 \mathrm{~L}$ at the indicated times is shown as fold difference relative to that at time 0 . a

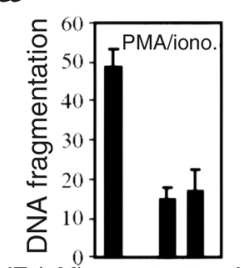

b
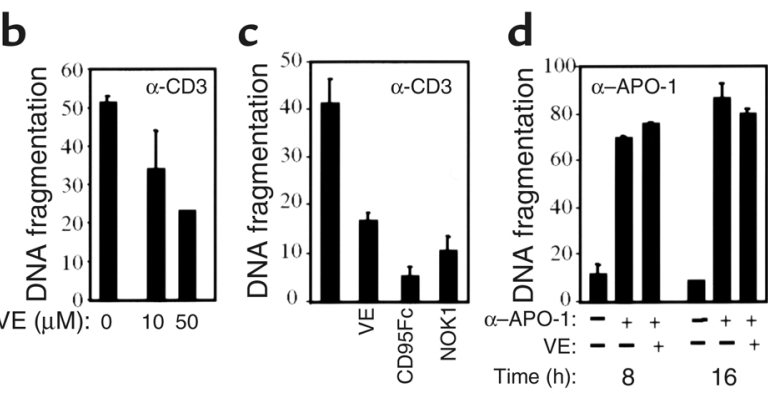

e

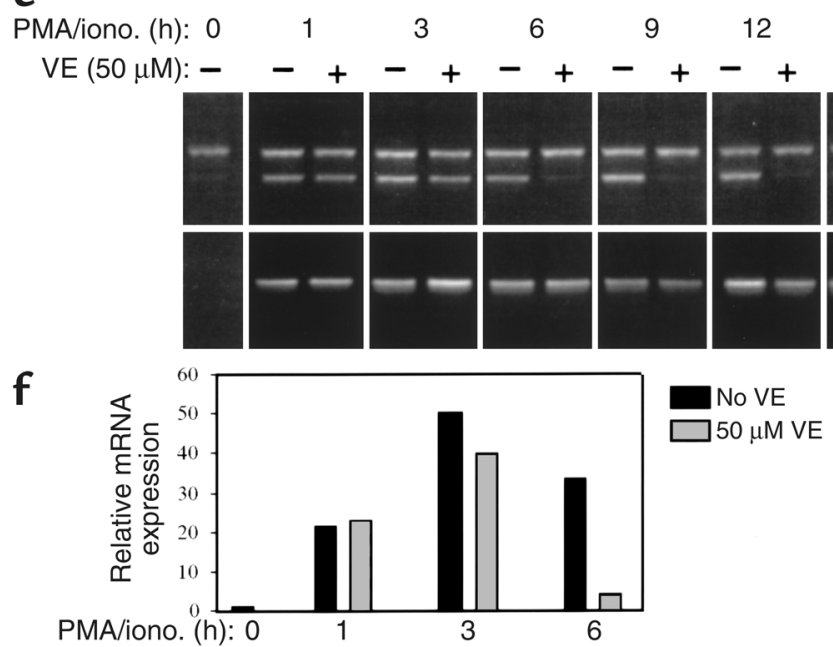


hours after stimulation (Figure 3f). In contrast, the levels of IFN- $\gamma$ mRNA were not significantly changed (Figure 3e). Thus, vitamin E may reduce CD95L expression at the transcriptional level and, therefore, attenuate AICD in J-27 cells.

Vitamin E blocks NF- $\kappa B$ and AP-1 binding to the CD95L promoter. Previously, we and others have demonstrated that the human CD95L promoter is regulated by several transcription factors, including AP-1 (26) and NF- $\kappa B$ (28). In addition, TCR-mediated activationinduced and HIV Tat-enhanced CD95L expression involves NF- $\mathrm{KB}$ activity (28). AP-1 was shown to be involved in anticancer drug-induced CD95L expression (26). Recently, AP-1 was also found to upregulate CD95L expression in T cells (our unpublished data). $\mathrm{NF}-\mathrm{KB}$ and AP-1 activities can be induced through TCR stimulation. In addition, a vast array of stimuli including certain environmental stressors, such as phorbol esters (e.g., PMA), chemicals, ionizing and ultraviolet irradiation, chemotherapeutic agents, proto-oncogenes, and oxidative stress activate NF- $\mathrm{KB}$ and $\mathrm{AP}-1(30,31)$. Vitamin $\mathrm{E}$ has been implicated in influencing DNA binding and function of NF- $\mathrm{KB}$ and AP-1 $(32,33)$. Therefore, we investigated whether vitamin $\mathrm{E}$ affects NF- $\mathrm{KB}$ and $\mathrm{AP}-1$ binding to the CD95L promoter target sites. Nuclear extracts were prepared from J-27 $\mathrm{T}$ cells stimulated in the presence or absence of vitamin $\mathrm{E}$. The NF- $\mathrm{\kappa B}$ and AP-1 binding sites contained in the CD95L promoter were used as probes in an EMSA. As has already been shown to occur, stimulation of $\mathrm{T}$ cells with PMA and ionomycin induced binding of nuclear factors to the NF- $\mathrm{KB}$ and AP-1 sites of the CD95L promoter (Figure 4a). Characterization of the inducible complexes formed on the CD95L probes by addition of antibodies against the $\mathrm{p} 50$ and p 65 subunits of NF- $\kappa B$, or the AP- 1 family members Jun and Fos, in EMSA, showed that these inducible binding complexes were either reduced or supershifted (Figure $4 \mathrm{~b}$ ). Thus, NF- $\kappa \mathrm{B}$ and AP- 1 family proteins were involved in formation of these inducible complexes. Addition of vitamin $\mathrm{E}$ prevented binding of $\mathrm{NF}-\mathrm{KB}$ and AP-1 to their binding sites (Figure 4a). As a control, the constitutive transcription factor NF-Y was not affected by vitamin E (Figure 4a).

Vitamin E suppresses $C D 95 L$ promoter activity. To further investigate the effect of vitamin $\mathrm{E}$ on $\mathrm{CD} 95 \mathrm{~L}$ expression, the CD95L promoter $(-860$ to +100$)$ or a minimal TATA promoter containing three copies of either the $\mathrm{NF}-\mathrm{KB}$ or the AP-1 site of the CD95L promoter was linked to the luciferase reporter gene, and these constructs were transiently transfected into J-27 $\mathrm{T}$ cells. After transfection, the cells were stimulated in the absence or presence of vitamin E. In accordance with the above data, vitamin E greatly reduced luciferase

\section{Figure 4}

Vitamin $\mathrm{E}$ blocks binding of NF- $\mathrm{KB}$ and $\mathrm{AP}-1$ to the CD95L promoter target sites. (a) ${ }^{32} \mathrm{P}$-labeled oligonucleotides containing the CD95L NF- $\mathrm{KB}$ (at the promoter -530 and -50 region) and $\mathrm{AP}-1$ (at the promoter +90 region) binding sequences were analyzed by EMSA. Nuclear extracts were prepared from J-27 T cells either not induced $(-)$ or induced $(+)$ by PMA and ionomycin in the absence $(-)$ or presence $\left(^{+}\right)$of vita$\min \mathrm{E}$. The inducible complexes corresponding to NF-KB and AP-1 are indicated. An NF-Y binding oligonucleotide was used for equal loading of nuclear extracts. (b) EMSA was carried out in the absence (-) or presence $(+)$ of the antibodies indicated.

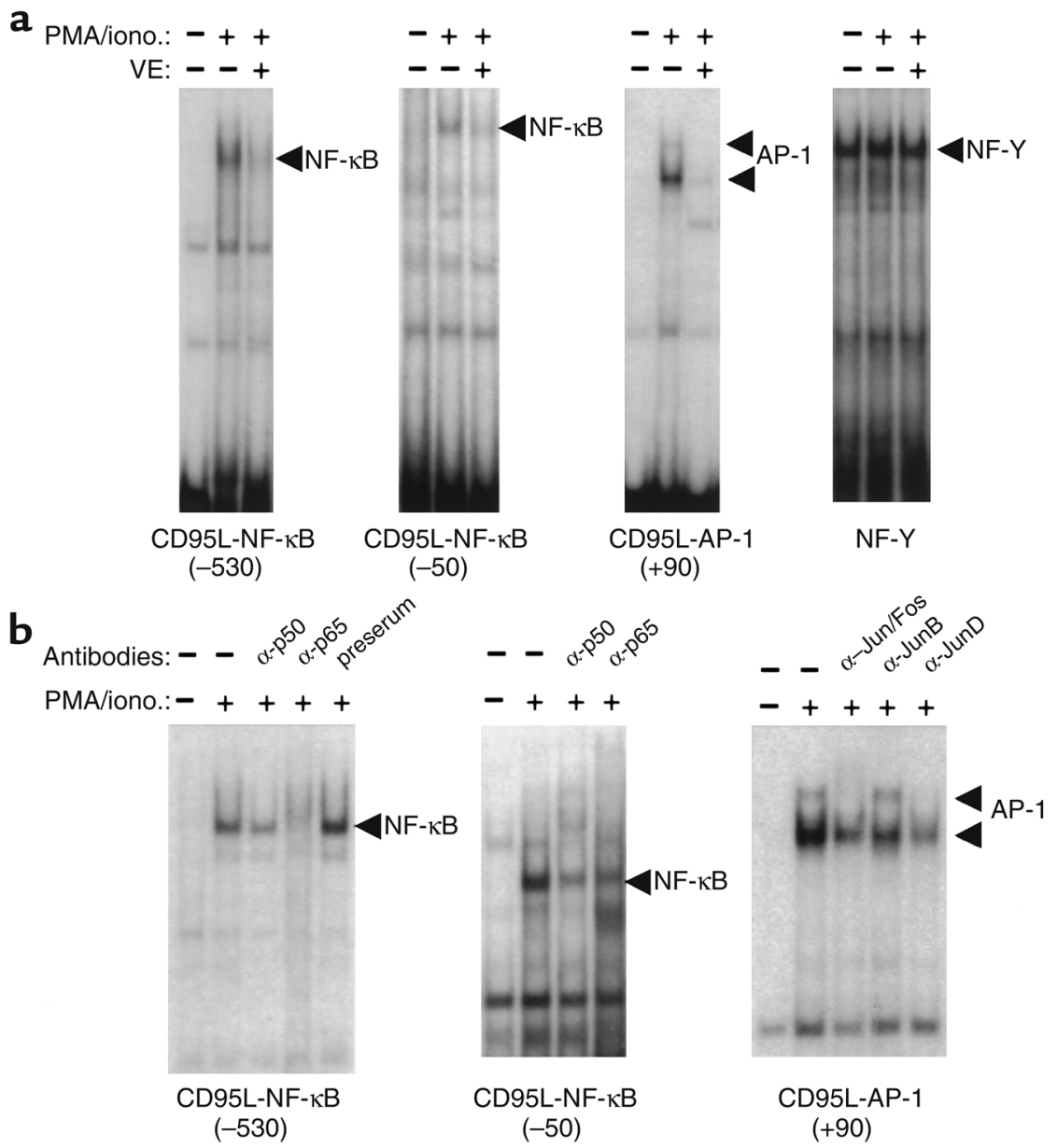



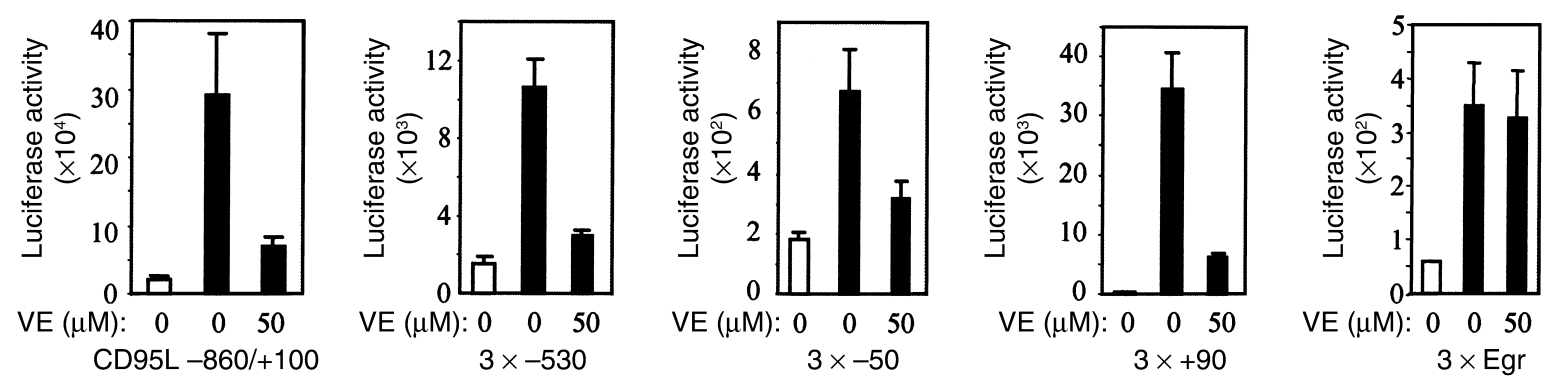

Figure 5

Vitamin E downregulates the CD95L promoter and CD95L NF- KB- or CD95L AP-1-mediated transcriptional activity. J-27 T cells were transiently transfected with the luciferase reporter constructs containing the $0.86-k b C D 95 \mathrm{~L}$ promoter, or three copies of the NF- $\mathrm{KB}$ binding sites at the -530 or -50 region or of the AP- 1 motif at the +90 region of the CD $95 \mathrm{~L}$ promoter. A luciferase reporter construct containing three copies of the Egr consensus binding site was used as a control. After overnight culture, the cells were divided and treated with vitamin $E$ or the vitamin E solvent ethanol for 1 hour and then further cultured in the absence (white bars) or presence (black bars) of PMA and ionomycin. Luciferase activity was determined after 8 hours of stimulation. Results represent the average of three to five independent transfection experiments.

expression driven by the CD95L promoter or by the NF- $\mathrm{KB}$ and the AP-1 site of the CD95L promoter (Figure 5). In controls, vitamin $\mathrm{E}$ did not affect luciferase expression driven by the Egr binding site (Figure 5).

Vitamin E reduces $C D 95 \mathrm{~L} m R N A$ levels in peripheral blood $T$ cells of HIV-positive individuals. Recent studies have demonstrated that CD95/CD95L interactions are involved in AICD of T cells in HIV-positive individuals $(34,35)$. T cells from HIV-infected patients exhibit both increased CD95 and CD95L expression and enhanced susceptibility to CD95-mediated apoptosis (34-38). Therefore, we investigated whether vitamin E could block CD95L expression in the peripheral blood lymphocytes of HIV-positive individuals. Peripheral blood lymphocytes from such individuals were subjected to analysis of CD95L mRNA expression levels in the absence or the presence of vitamin E. Different levels of CD95L mRNA expression were found in lymphocytes from different HIV-positive individuals examined. Data from five representative HIV-positive individuals are presented in Figure 6a. In some HIV-positive indi- viduals, e.g., donors 1 and 2 , like in uninfected individuals, no or very little CD95L mRNA was expressed in unstimulated cells and CD95L transcripts were significantly upregulated upon $\alpha$-CD3 stimulation. In other HIV-positive individuals, e.g., donors 3, 4, and 5, however, CD95L mRNA expression was readily detectable in unstimulated cells and was further increased upon TCR engagement. Nevertheless, in the presence of 25 $\mu \mathrm{M}$ vitamin E, expression of CD95L mRNA was completely blocked in most cases (Figure 6a). $T$ cells from donors 1-4 were further subjected to analysis of the correlation between CD95L transcription levels and sensitivity to AICD. No significant apoptosis induction was seen in T cells from donors 1 and 2 upon $\alpha$-CD3 stimulation (data not shown; see Discussion). T cells from donors 3 and 4 were susceptible to AICD (Figure $6 \mathrm{~b})$. AICD of these cells was partially blocked by CD95Fc. Vitamin E was shown to suppress apoptotic death of $\mathrm{T}$ cells from donor 3 to an extent similar to that brought about by CD95Fc. Complete inhibition of $\alpha$-CD3-induced AICD by vitamin $E$ was seen in T

\section{Figure 6}

Vitamin E reduces CD95L mRNA levels in peripheral blood T cells of HIV-positive individuals. (a) CD95L mRNA levels in peripheral blood T lymphocytes of HIV-positive individuals are downregulated by vitamin E. Freshly isolated peripheral blood T lymphocytes from HIV-positive individuals were either left alone or pretreated with vitamin $E$ and then stimulated with plate-bound $\alpha$-CD3 for 12 hours. CD95L mRNA levels were examined by RT-PCR. Results from five individuals are shown. (b) Effect of vitamin E on AICD. T cells from above donors were either left alone or stimulated with $\alpha-C D 3$ in the absence or presence of CD95Fc, control human IgG1, or vitamin $\mathrm{E}(25 \mu \mathrm{M})$. Cell death was assessed after a further 48 hours by propidium iodide uptake. Data from donors 3 and 4 are shown.

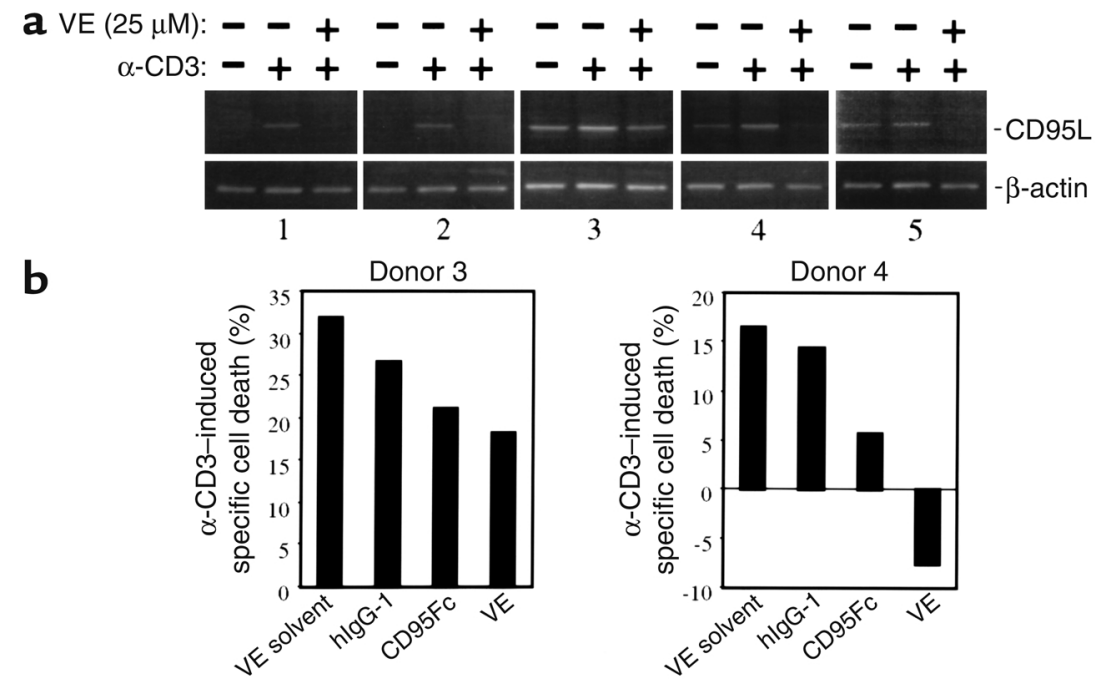


cells from donor 4 (Figure 6b). Thus, inhibition of CD95L mRNA expression may partially account for suppression of AICD by vitamin E.

Vitamin E inhibits apoptosis of peripheral blood T cells of HIVpositive individuals. To determine whether vitamin $\mathrm{E}$ could reduce depletion of T cells from HIV-positive individuals, we next analyzed the effect of vitamin E on AICD in peripheral blood lymphocytes of such individuals. Table 1 shows the medical history and the mean values of total lymphocytes and $\mathrm{CD}^{+}$and $\mathrm{CD} 4^{+} \mathrm{T}$ cells in these cases. As opposed to lymphocytes from uninfected donors, lymphocytes isolated from HIV-infected individuals were more susceptible to apoptosis (Figure 7a). Apoptosis of T cells from HIV-positive individuals could partially be blocked by CD95Fc, demonstrating that a fraction of $\mathrm{T}$ cells underwent CD95/CD95L-mediated apoptosis. Different levels of inhibition of AICD by CD95Fc were seen in 19 of $31 \mathrm{HIV}$-positive patients tested. Among these 19 patients, $41-85 \%$ inhibition of AICD by CD95Fc was seen in five and $21-40 \%$ inhibition in six patients (Figure 7, $b$ and $d$ ). Inhibition of AICD by vitamin $\mathrm{E}$ was also observed in 55\% of HIV-positive donors. Vitamin E led to a slightly greater inhibition of AICD than did CD95Fc in four patients and a significantly greater inhibition than did CD95Fc in nine patients (Figure 7, $\mathrm{c}$ and d). Statistical analysis showed that the vitamin $\mathrm{E}$ effect was not dependent on age, sex, viral load, stage of disease, or therapy.

\section{Discussion}

In this study, we show that vitamin E suppresses CD95L promoter activity by downregulation of transcriptional activity of NF- $\mathrm{KB}$ and AP-1 and, consequently, downregulates CD95L mRNA expression and CD95-mediated AICD. Vitamin E is a principal chainbreaking antioxidant in biological membranes (16). Activities of NF- $\mathrm{KB}$ and AP-1 are largely affected by the cellular oxidation/reduction (redox) status $(30,31)$. Therefore, vitamin $E$ may block the early signal for activation of NF- $\kappa B$ and AP-1. Vitamin $E$ was also shown to inhibit translocation of protein kinase $\mathrm{C}$ (PKC), a crucial enzyme involved in cellular signal transduction, to the membrane of cells stimulated by phorbol esters and also to inhibit its phosphorylation activity (39). Since PKC is essential for NF- $\mathrm{KB}$ and AP- 1 activation (40-42), inhibition of PKC function by vitamin E may be one of the mechanisms by which vitamin $\mathrm{E}$ interferes with activation of NF- $\kappa \mathrm{B}$ and AP-1.

We observed that vitamin $\mathrm{E}$ had little inhibitory effect on CD95L transcription at the early activation time points (1-3 hours) but a strong effect at later time points. However, suppression of NF- $\kappa B$ and AP-1 DNA binding activity by vitamin $\mathrm{E}$ could be detected at the early activation stages. This discrepancy may be due to the fact that the CD95L promoter activity is regulated by multiple transcription factors (43). It has been shown that transcription factors such as NF-AT and
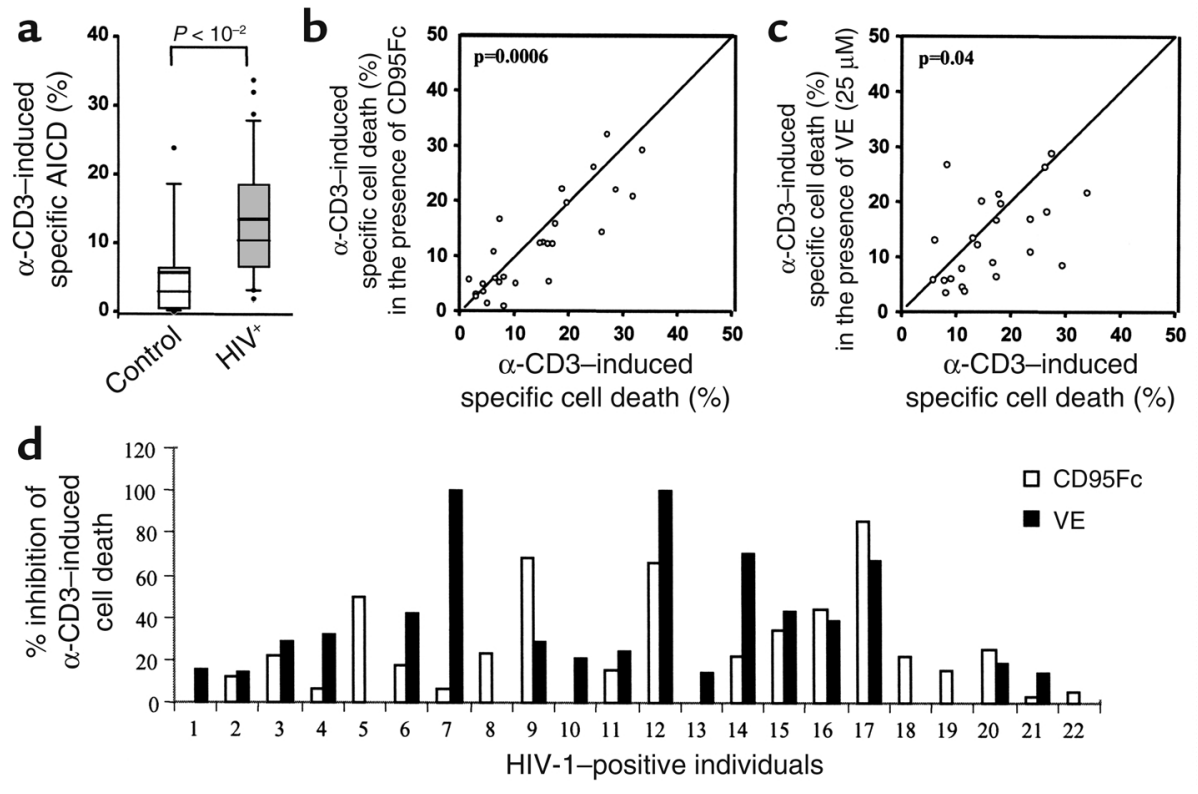

\section{Figure 7}

Effect of vitamin E on AICD of peripheral blood lymphocytes of HIV-positive individuals. (a) AICD is increased in HIV-infected individuals. Peripheral blood T lymphocytes from 33 HIV-positive individuals and 11 uninfected donors were stimulated with plate-bound $\alpha$-CD3 for 48 hours. Apoptosis was assessed by FSC/SSC analysis. The mean difference between patients and uninfected individuals is -7.23 . The $95 \%$ confidence interval is -13.7 to -2.12 . ( $\mathbf{b}$ and $\mathbf{c}$ ) Vitamin E prevents AICD of T lymphocytes of HIV-positive individuals. Freshly isolated blood T lymphocytes from $31 \mathrm{HIV}$-positive individuals were individually stimulated with plate-bound $\alpha$-CD3 in the absence ( $x$ axis) or presence ( $y$ axis) of either CD95Fc (b, 27 patients) or vitamin E (c, 24 patients) as indicated. IgG1 was used as control. Cell death was assessed after 48 hours' stimulation and subjected to statistical analysis. (d) Comparison of CD95Fc-and vitamin E-mediated inhibition of $\alpha$-CD3-induced specific cell death of HIV-positive individuals. AICD from 22 of $31 \mathrm{HIV}$-positive individuals tested was downregulated in the presence of either CD95Fc or vitamin E. Results are presented as percent inhibition of $\alpha$-CD3-induced specific cell death by CD95Fc or by vitamin E. 
Table 1

Characteristics of patients

\begin{tabular}{|c|c|c|}
\hline & Uninfected donors ${ }^{A}$ & HIV-1+ individuals \\
\hline No. of patients & 11 & 35 \\
\hline Age (years) ${ }^{B}$ & $26 \pm 6$ & $42 \pm 12$ \\
\hline $\operatorname{Sex}(F / M)$ & $6 / 5$ & $5 / 30$ \\
\hline Viral load (log copies/ml) $)^{B, C}$ & ND & $4.24 \pm 4.26$ \\
\hline $\mathrm{CD}^{+}$cells $(\text {cells } / \mu \mathrm{I})^{\mathrm{B}}$ & ND & $446 \pm 287$ \\
\hline $\mathrm{CD}^{+}$cells $(\text {cells } / \mu \mathrm{l})^{\mathrm{B}}$ & ND & $1,221 \pm 544$ \\
\hline $\mathrm{CD}^{+} / \mathrm{CD}^{+}$ratio $^{\mathrm{B}}$ & $N D^{D}$ & $0.41 \pm 0.25$ \\
\hline Lymphocytes $(\text { cells } / \mu \mathrm{l})^{\mathrm{B}}$ & $N D^{D}$ & $2,041 \pm 910$ \\
\hline Treatment & $\mathrm{HA}$ & $\begin{array}{l}\quad \text { Naive }(n=6) \\
\text { ART, double }{ }^{\mathrm{E}}(n=4) \\
\text { ART, triple } \mathrm{e}^{\mathrm{E}}(n=15) \\
\text { ART, }_{\text {triple }}^{\mathrm{E}}+\mathrm{PI}(n=10)\end{array}$ \\
\hline Stage $(C D C 1993)^{F}$ & B & $\begin{array}{c}\mathrm{A} 1(n=1) \\
\text { 31/B2/B3 }(n=1 / 25 / 1) \\
\text { C3 }(n=7)\end{array}$ \\
\hline
\end{tabular}

Infected and uninfected donors were recruited from September to December 2000. Approval was given by the local ethics committee. Ap24-negative. ${ }^{B} \mathrm{Num}-$ bers are mean \pm SD. CIn 16 individuals, viral load was below 50 copies $/ \mathrm{ml}$ (detection limit) by bDNA test (Chiron Corporation, Emeryville, California, USA). DIn general, total lymphocytes of healthy individuals are 2,182 \pm 605 , and $\mathrm{CD}^{+} / \mathrm{CD}^{+}$ratio is $1,055 \pm 0.49$. E"Double" and "triple" indicate combinations of two or three nucleoside or non-nucleoside analogues. ${ }^{\mathrm{F}} \mathrm{CDC}$ 1993, Centers of Disease Control classification of 1993. ND, non-determined; ART, antiretroviral therapy; HAART, highly active ART; PI, protease inhibitor.

Egr-2,3 also play an important role in $\mathrm{T}$ cell activationinduced CD95L expression. Targeting NF-AT activity using the immunosuppressive drug Cyclosporin A can block CD95L mRNA expression and consequently block AICD in T cells $(6,43)$. Thus, at the early activation time point, NF-AT and Egr transcription factors might play a dominant role in CD95L transcription and mask the effect of vitamin E on NF- KB and AP-1. Alternatively, the decreased CD95L mRNA expression observed in the later activation time points might be partially due to a vitamin E-mediated posttranscriptional regulation of the CD95L mRNA stability.

NF- $\mathrm{KB}$ transcription factors are key regulators of immune, inflammatory, and acute phase responses and are also implicated in the control of cell proliferation and apoptotic signaling. NF- $\mathrm{KB}$ activities can be induced by a vast array of stimuli, including TCR stimulation, certain environmental stressors, chemicals, ionizing and ultraviolet irradiation, chemotherapeutic agents, proto-oncogenes, and oxidative stress $(30,31)$. However, the role of NF- $\mathrm{\kappa B}$ in apoptosis remains controversial: it may accelerate apoptosis or, as is perhaps more commonly believed, it may protect cells from programmed cell death (for review see ref. 44). Whether $\mathrm{NF}-\mathrm{KB}$ promotes or inhibits apoptosis appears to depend on the specific cell type and the type of inducer. Our study provides clear evidence showing the proapoptotic role of NF- $\mathrm{KB}$ in AICD in T cells.

Freshly isolated $\mathrm{T}$ cells from healthy donors are resistant to AICD, but they become susceptible to AICD after stimulation (24). To study AICD in normal $\mathrm{T}$ cells, we therefore used preactivated day $6 \mathrm{~T}$ cells. In contrast, freshly isolated $\mathrm{T}$ cells from HIV-infected individuals were more susceptible to apoptosis (Figure 7a). Most probably, T cells from HIV-positive individuals are preactivated. Analysis of CD95L mRNA expression in HIV-infected individuals revealed that, in many cases, CD95L mRNA expression was readily detectable in unstimulated cells and was further increased upon TCR engagement. T cells from these individuals were susceptible to AICD. In some HIVpositive individuals, like in uninfected individuals, no or very little CD95L mRNA was expressed in unstimulated cells, and CD95L transcripts were upregulated upon $\alpha$-CD3 stimulation. Analysis of susceptibility of these $\mathrm{T}$ cells (from two donors) to apoptosis showed no AICD upon $\alpha$-CD3 stimulation. We speculate that these $T$ cells might be at an activation stage similar to that of normal resting $\mathrm{T}$ cells. These observations, however, should be extended to a larger number of HIV-positive individuals in order to explore the possible correlation between levels of apoptosis and levels of CD95L transcription.

$T$ cell depletion plays a central role in the pathogenesis of AIDS. It has been observed that important links exist between vitamin E deficiency, HIV infection, and risk of progression to AIDS (19-22). Furthermore, supplementation of vitamin $\mathrm{E}$ in the diet was shown to increase $\mathrm{CD}^{+} \mathrm{T}$ cell counts $(13-15)$. Thus, vitamin $\mathrm{E}$ has been advocated by some investigators to support AIDS therapy $(21,45)$. Although a decrease of apoptosis in HIV-infected cells treated with some antioxidants has been observed, little is known about the molecular mechanism involved. We show here a molecular mechanism by which vitamin E downregulates CD95L expression and thereby partially blocks AICD in T cells from HIV-positive individuals. Our study may encourage further clinical investigation to address whether vitamin E supplementation could have important effects on $T$ cell survival in vivo and whether vitamin E could improve the life quality of AIDS patients during therapy.

CD95/CD95 L interaction has been considered as a cause of AICD of T cells. However, CD95-deficient cells were found to die by TCR-induced apoptosis, which could be inhibited by TNF antagonists $(46,47)$. This indicates that $\mathrm{T}$ cell apoptosis is not solely regulated by the CD95 system. Elevated serum TNF levels are seen in HIV-infected individuals $(48,49)$. However, little is known about the ability of TNF to induce apoptosis in HIV-infected T cells. Administration of CD95, TNF, or TRAIL/APO-2L (TNF-related apoptosis-inducing ligand) antagonists was shown to reduce AICD in T cells from patients infected with HIV, suggesting that signals from these three death systems may be involved in $\mathrm{T}$ cell AICD (50). Our data show that AICD was not inhibited by CD95Fc in $40 \%$ of HIV-1-positive individuals tested. CD95Fc also did not completely block AICD in many HIV-positive individuals, suggesting that other TNF family members may be involved in apoptotic death of $T$ cells. In addition, we found that, in $50 \%$ of the HIV-1-positive individuals tested, higher 
levels of inhibition of T cell AICD were achieved with vitamin $\mathrm{E}$ treatment than with $\mathrm{CD} 95 \mathrm{Fc}$ treatment. This observation suggests that vitamin E may also block CD95-independent apoptosis.

Recently, retinoic acid (a metabolite of vitamin A) has been shown to inhibit CD95L expression and $\alpha$-CD3induced apoptosis in T cells (51-53). Retinoic acid exerts its effect through two intracellular nuclear hormone receptors: retinoic acid receptors (RARs) and the retinoid $\mathrm{X}$ receptors (RxRs). Inhibition of CD95L and AICD in T cells by retinoic acid requires both the RAR and the RxR pathways (52). Although reduced CD95L expression in $\mathrm{T}$ cells was detected at the mRNA and protein levels, no retinoid receptor response elements could be found in the published promoter regions of CD95 and CD95L (52). Recently, several studies reported that retinoid acid also upregulates CD95 and CD95L expression in different cell types (54-58). Thus, the molecular mechanism by which retinoic acid suppresses $\mathrm{CD} 95 \mathrm{~L}$ expression in $\mathrm{T}$ cells remains unclear. The data on vitamin $\mathrm{E}$ reported in this paper, however, clarify an important mechanism of action on suppression of the CD95 death system.

\section{Acknowledgments}

We thank A. Benner for the statistical evaluation, and H. zur Hausen, S. Desriviers, S. Kirchhoff, W. Dröge, and A. Martin for critical reading of the manuscript.

1. Krammer, P.H., Galle, P.R., Moller, P., and Debatin, K.M. 1998. CD95 (APO-1/Fas)-mediated apoptosis in normal and malignant liver, colon, and hematopoietic cells. Adv. Cancer Res. 75:251-273.

2. Suda, T., Takahashi, T., Golstein, P., and Nagata, S. 1993. Molecular cloning and expression of the Fas ligand, a novel member of the TNF family. Cell. 75:1169-1178.

3. Griffith, T.S., Brunner, T., Fletcher, S.M., Green, D.R., and Ferguson, T.A. 1995. Fas ligand-induced apoptosis as a mechanism of immune privilege. Science. 270:1189-1192.

4. Alderson, M.R., et al. 1995. Fas ligand mediates activation-induced cell death in human T lymphocytes. J. Exp. Med. 181:71-77.

5. Brunner, T., et al. 1995. Cell-autonomous Fas (CD95)/Fas-ligand interaction mediates activation-induced apoptosis in T-cell hybridomas. Nature. 373:441-444.

6. Dhein, J., Walczak, H., Baümler, C., Debatin, K.M., and Krammer, P.H. 1995. Autocrine T-cell suicide mediated by APO-1(Fas/CD95). Nature. 373:438-441.

7. Ju, S.T., et al. 1995. Fas (CD95)/FasL interactions required for programmed cell death after T-cell activation. Nature. 373:444-448.

8. Finkel, T.H., et al. 1995. Apoptosis occurs predominantly in bystander cells and not in productively infected cells of HIV- and SIV-infected lymph nodes. Nat. Med. 1:129-134.

9. Gougeon, M.L., and Montagnier, L. 1999. Programmed cell death as a mechanism of CD4 and CD8 T cell deletion in AIDS. Molecular control and effect of highly active anti-retroviral therapy. Ann. N.Y. Acad. Sci. 887:199-212.

10. Badley, A.D., Pilon, A.A., Landay, A., and Lynch, D. 2000. Mechanisms of HIV-associated lymphocyte apoptosis. Blood. 96:2951-2964.

11. Treitinger, A., et al. 2000. Decreased antioxidant defence in individuals infected by the human immunodeficiency virus. Eur. J. Clin. Invest. 30:454-459.

12. Favier, A., Sappey, C., Leclerc, P., Faure, P., and Micoud, M. 1994. Antioxidant status and lipid eroxidation in patients infected with HIV. Chem. Biol. Interact. 91:165-180.

13. Odeleye, O.E., and Watson, R.R. 1991. The potential role of vitamin E in the treatment of immunological abnormalities during acquired immune deficiency syndrome. Prog. Food Nutr. Sci. 15:1-19.

14. Moriguchi, S., et al. 1993. Vitamin E is an important factor in T cell differentiation in thymus of F344 rats. J. Nutr. Sci. Vitaminol. (Tokyo). 39:451-463.

15. Tang, A.M., Graham, N.M.H., Semba, R.D., and Saah, A.J. 1997. Asso- ciation between serum vitamin A and $\mathrm{E}$ levels and HIV-1 disease progression. AIDS. 11:613-620.

16. Liebler, D.C. 1993. The role of metabolism in the antioxidant function of vitamin E. Crit. Rev. Toxicol. 23:147-169.

17. Beharka, A., Redican, S., Leka, L., and Meydani, S.N. 1997. Vitamin E status and immune function. Methods Enzymol. 282:247-263.

18. Moriguchi, S., and Muraga, M. 2000. Vitamin and immunity. Vitam. Horm. 59:305-336.

19. Liang, B., Chung, S., Araghiniknam, M., Lane, L.C., and Watson, R.R. 1996. Vitamins and immunomodulation in AIDS. Nutrition. 12:1-7.

20. Abrams, B., Duncan, D., Hertz-Picciotto, I. 1993. A prospective study of dietary intake and acquired immune deficiency syndrome in HIVseropositive homosexual men. J. Acquir. Immune Defic. Syndr. 6:949-958.

21. Wang, Y., and Watson, R.R. 1994. Potential therapeutics of vitamin E (tocopherol) in AIDS and HIV. Drugs. 48:327-338.

22. Wang, Y., Huang, D.S., Liang, B., and Watson, R.R. 1994. Nutritional status and immune response in mice with murine AIDS are normalized by vitamin E supplementation. J. Nutr. 124:2024-2032.

23. Krammer, P.H. 2000. CD95's deadly mission in the immune system. Nature. 407:789-795.

24. Klas, C., Debatin, K.M., Jonker, R.R., and Krammer, P.H. 1993. Activation interferes with the APO-1 pathway in mature human T cells. Int. Immunol. 5:625-630.

25. Sprick, M.R., et al. 2000. FADD/MORT1 and caspase- 8 are recruited to TRAIL receptors 1 and 2 and are essential for apoptosis mediated by TRAIL receptor 2. Immunity. 12:599-609.

26. Eichhorst, S.T., et al. 2000. A novel AP-1 element in the CD95 ligand promoter is required for induction of apoptosis in hepatocellular carcinoma cells upon treatment with anticancer drugs. Mol. Cell. Biol. 20:7826-7837.

27. Heid, C.A., Stevens, J., Livak, K.J., and Williams, P.M. 1996. Real time quantitative PCR. Genome Res. 6:986-994.

28. Li-Weber, M., Laur, O., Dern, K., and Krammer, P.H. 2000. T cell activation-induced and HIV Tat-enhanced CD95(APO-1/Fas) ligand transcription involves NF-אB. Eur. J. Immunol. 30:661-670.

29. Stuart, M.J. 1982. Vitamin E deficiency: its effect on platelet-vascular interaction in various pathologic states. Ann. N.Y. Acad. Sci. 393:277-288.

30. Gius, D., Botero, A., Shah, S., and Curry, H.A. 1999. Intracellular oxidation/reduction status in the regulation of transcription factors NF- $\kappa \mathrm{B}$ and AP-1. Toxicol. Lett. 106:93-106.

31. Mercurio, F., and Manning, A.M. 1999. NF- $\mathrm{KB}$ as a primary regulator of the stress response. Oncogene. 18:6163-6171.

32. Azzi, A., et al. 1995. Vitamin E: a sensor and an information transducer of the cell oxidation state. Am. J. Clin. Nutr. 62(Suppl. 6):1337S-1346S.

33. Suzuki, Y.J., and Packer, L. 1993. Inhibition of NF- $\kappa$ B activation by vitamin E derivatives. Biochem. Biophys. Res. Commun. 193:277-283.

34. Kaplan, D., and Sieg, S. 1998. Role of the Fas/Fas ligand apoptotic pathway in human immunodeficiency virus type 1 disease. J. Virol. 72:6279-6282

35. Famularo, G., Nucera, E., Marcellini, S., and De Simone, C. 1999. Fas/Fas ligand on the road: an apoptotic pathway common to AIDS, autoimmunity, lymphoproliferation and transplantation. Med. Hypotheses. 53:50-62.

36. Li, C.J., Friedman, D.J., Wang, C., Metelev, V., and Pardee, A.B. 1995. Induction of apoptosis in uninfected lymphocytes by HIV-1 Tat protein. Science. 268:419-431.

37. Bäumler, C.B., et al. 1996. Activation of the CD95 (APO-1/Fas) system in $T$ cells from human immunodeficiency virus type-1-infected children. Blood. 88:1741-1746.

38. Sloand, E.M., et al. 1997. Role of Fas ligand and receptor in the mechanism of T-cell depletion in AIDS: effect on CD4+ lymphocyte depletion and HIV replication. Blood. 89:1357-1363.

39. Boscoboinik, D., Szewczyk, A., Hensey, C., and Azzi, A. 1991. Inhibition of cell proliferation by $\alpha$-tocopherol. Role of protein kinase C. J. Biol. Chem. 266:6188-6194.

40. Baier-Bitterlich, G., et al. 1996. Protein kinase C- $\theta$ isoenzyme selective stimulation of the transcription factor complex AP-1 in T lymphocytes. Mol. Cell. Biol. 16:1842-1850.

41. Sun, Z., et al. 2000. PKC- $\theta$ is required for TCR-induced NF- $\kappa B$ activation in mature but not immature T lymphocytes. Nature. 404:402-407.

42. Schraven, B., Marie-Cardine, A., Hübener, C., Bruyns, E., and Ding, I. 1999. Integration of receptor-mediated signals in T cells by transmembrane adaptor proteins. Immunol. Today. 20:431-434.

43. Li-Weber, M., and Krammer, P.H. 2002. The death of a T-cell: expression of the CD95 ligand. Cell Death Differ. 9:101-103.

44. Barkett, M., and Gilmore, T.D. 1999. Control of apoptosis by Rel/ NF- $\kappa \mathrm{B}$ transcription factors. Oncogene. 18:6910-6924.

45. Baum, M.K., et al. 1992. Influence of HIV infection on vitamin status and requirements. Ann. N.Y. Acad. Sci. 699:165-173. 
46. Zheng, L., et al. 1995. Induction of apoptosis in mature T cells by tumour necrosis factor. Nature. 377:348-351.

47. Tucek-Szabo, C.L., et al. 1996. Surface T cell Fas receptor/CD95 regulation, in vivo activation, and apoptosis: activation-induced death can occur without Fas receptor. J. Immunol. 156:192-200.

48. Chollet-Martin, S., et al. 1994. Comparison of plasma cytokine levels in African patients with HIV-1 and HIV-2 infection. AIDS. 8:879-884.

49. Ayehunie, S., et al. 1993. Raised levels of tumor necrosis factor-alpha and neopterin, but not interferon-alpha, in serum of HIV-1 infected patients from Ethiopia. Clin. Exp. Immunol. 91:37-42.

50. Katsikis, P.D., et al. 1997. Interleukin-1 beta converting enzyme-like protease involvement in Fas-induced and activation-induced peripheral blood $\mathrm{T}$ cell apoptosis in HIV infection: TNF-related apoptosisinducing ligand can mediate activation-induced $\mathrm{T}$ cell death in HIV infection. J. Exp. Med. 186:1365-1372.

51. Yang, Y., Mercep, M., Ware, C.F., and Ashwell, J.D. 1995. Fas and activation-induced Fas ligand mediate apoptosis of $\mathrm{T}$ cell hybridomas: inhibition of Fas ligand expression by retinoic acid and glucocorticoids. J. Exp. Med. 181:1673-1682.

52. Bissonnette, R.P., et al. 1995. 9-cis retinoic acid inhibition of activation-induced apoptosis is mediated via regulation of Fas ligand and requires retinoic acid receptor and retinoid $\mathrm{X}$ receptor activation.
Mol. Cell. Biol. 15:5576-5585.

53. Yang, Y., Bailey, J., Vacchio, M.S., Yarchoan, R., and Ashwell, J.D. 1995 Retinoic acid inhibition of ex vivo human immunodeficiency virusassociated apoptosis of peripheral blood cells. Proc. Natl. Acad. Sci. USA. 92:3051-3055.

54. Guan, W.Q., Yu, S.F., and Gao, Y. 2000. Alteration of Fas/FasL expression of oral squamous cell carcinoma cell line Tca83 induced by retinoic acid. Chin. J. Dent. Res. 3:35-39.

55. Zeng, H., Zhao, X., and Ma, Y. 1998. Retinoic acid inducing Fas expression in HL-60 cells. Zhoghua Xue Ye Xue Za Zhi. 19:237-240.

56. Saitoh, A., et al. 2000. Selective upregulation of fibroblast Fas ligand expression, and prolongation of Fas/Fas ligand-mediated skin allograft survival, by retinoic acid: the skin as a retinoide-inducible immune privilege site. J. Invest. Dermatol. 115:154-161.

57. Okamura, T., et al. 1998. All-trans retinoic acid modulates Fas antigen expression and affects cell proliferation and apoptosis in combination with anti-Fas monoclonal antibody in the human myelom cell line, U266B1. Exp. Hematol. 26:501-506.

58. Muschen, M., Warskulat, U., Schmidt, B., Schulz, W.A., and Haussinger, D. 1998. Regulation of CD95 (APO-1/Fas) ligand and receptor expression in human embryonal carcinoma cells by interferon gamma and all-trans retinoic acid. Biol. Chem. 379:1083-1091. 